\title{
EDUCAÇÃO NUTRICIONAL NA ESCOLA DO PRIMEIRO GRAU: UMA PROPOSIÇÃO PARA PERNAMBUCO (BRASIL) *
}

\author{
Eronides da Silva Lima "* \\ Emília Aureliano de Alencar Monteiro* * \\ Astrogilda Paes de Andrade* ***
}

LIMA, E. da $\mathbf{S}$, et al. Educaçăo nutricional na escola do primeiro grau: uma proposição para Pernambuco (Brasil). Rev. Saúde públ., S. Paulo, 20:62-82, 1986.

\begin{abstract}
RESUMO: Propõe-se um modelo de ensino em nutrição para a escola do primeiro grau do Estado de Pernambuco (Brasil). Com base no estudo da proposta curricular de ciências que contém "Programas de Saúde", e nos resultados da pesquisa realizada com alunos da oitava série e professores da área metropolitana de Recife, elaborou-se um programa de ensino em nutrição que representa os temas sugeridos pelos alunos. Esta fase compreendeu: seleção de objetivos; seleção e organização do conteúdo; seleção de técnicas; recursos e instrumentos de avaliação, considerando os aspectos de logicidade, gradualidade, continuidade e integração. Os seguintes objetivos gerais de cada série nortearam a seleção e organização dos temas: a) Primeira série - Identificar a interdependência entre: ambiente, homem e alimento; b) Segunda série - Classificar os alimentos conforme a sua origem e função e identificar os recursos alimentares da comunidade; c) Terceira série - Agrupar os alimentos conforme a predominância de substâncias nutritivas e sua função no organismo e identificar os recursos alimentares do município; d) Quarta série - Identificar formas de higiene e conservação de alimentos e a produção agrícola e pecuária do Estado; e) Quinta série - Conhecer normas gerais de inspeção industrial e sanitária de alimentos; f) Sexta série - Conhecer as preparaçōes habituais e típicas de região, bem como outras formas de utilização das fontes alimentares disponíveis e respectivas formas de preparo e cozimento; g) Sétima série - Identificar os fatores que interferem no acesso e utilização de uma dieta adequada às necessidades nutricionais de uma comunidade; h) Oitava série - Conhecer as doenças nutricionais mais frequientes em Pernambuco e no Brasil, seus fatores determinantes, consequiências e medidas preventivas adotadas. O programa proposto pode ser agregado ao "Programas de Saúde" correspondendo cada série a uma unidade entre as demais presentes nesta área de estudo.
\end{abstract}

UNITERMOS: Criança, nutrição. Educação em saúde. Escolares.

\section{INTRODUÇÃO}

O sistema educativo global é composto de três subsistemas: o informal, o formal e não-formal.

O informal é aquele que resulta da interação social entre diferentes grupos. A educação formal é sequiencial, sistematizada e se prolonga por vários anos, sen- do obrigatória para o nível primário. $\mathrm{O}$ subsistema não-formal corresponde aos meios de comunicação de massa e, como tal, seus objetivos estão perfeitamente de acordo com interesses: econômicos, políticos e sociais, nem sempre relacionados às finalidades da educação ${ }^{6}$.

" Parte da Dissertação "Educação Nutricional na Escola do Primeiro Grau: Uma Proposição para Pernambuco", apresentada ao Departamento de Nutrição da Universidade Federal de Pernambuco, para obtenção do Grau de Mestre em Nutrição e Saúde Pública. Apresentado ao VII Congresso Latino Americano de Nutrición, realizado em Brasília, em novembro de 1984.

Do Departamento de Nutrị̧ão e Saúde da Universidade Federal de Viçosa. Av. P.H. Rolfs s/n.o - 36.570 - Viçosa, MG - Brasil.

** Do Departamento de Nutrição da Universidade Federal de Pernambuco - Av. Prof. Moraes Rego, s/n. ${ }^{\circ}$ - 50000 - Recife, PE - Brasil.

Do Departamento de Métodos e Técnicas de Ensino da Universidade Federal de Pernambuco Av. Prof. Moraes Rego, s/n. 0 - 50.000 - Recife. PE - Brasil. 
LIMA, E. da S. et al. Educação nutricional na escola do primeiro grau: uma proposição para Pernambuco (Brasil). Rev. Saúde públ,, S. Paulo, 20:62-82, 1986.

No Brasil, a educação formal de primeiro grau é institucionalizada e se desenvolve de acordo com a Lei 5692/71 ?. Conforme o artigo $7^{\circ}$, desta lei, o item "Programas de Saúde" é incluído obrigatoriamente nos currículos plenos dos estabelecimentos de ensino de primeiro grau, podendo servir de instrumento ao presente estudo sobre a educação em nutrição, nesse nível de ensino.

No Estado de Pernambuco, o item "Programas de Saúde" é componente do núcleo comum e está inserido na Proposta Curricular de Ciências. Esta proposta pressupõe que o homem precisa desenvolver uma mente crítica, objetiva e racional, como requisitos que caracterizam uma atitude científica. $O$ ensino de ciências deve emergir de siutações-problema que sejam mais significativas e interessantes para o aluno, adequadas às suas necessidades ${ }^{9}$.

Entretanto, é evidente a desintegração do conteúdo de "Programas de Saúde" contido na Proposta Curricular de Ciências, no que se refere aos problemas reais de saúde da região: seus fatores determinantes, consequiências e possíveis alternativas para solucioná-los. Tais lacunas se ampliam quando se analisa o ensino da nutrição em "Programas de Saúde" pois apesar da incontestável prevalência da desnutrição em Pernambuco, inexiste na escola de primeiro grau um conteúdo sistematizado nessa área de estudo.

Por outro lado, admite-se que a proposta de inserção do aluno em sua realidade, inclui objetivos e conteúdos de ensino que representem fatos concretos da sua região, em suas relações de causaefieito dentro do contexto social geral.

Os resultados da pesquisa realizada com alunos da oitava série do primeiro grau, das escolas públicas e privadas da área metropolitana de Recife, permitem reforçar as afirmações acima, vez que o "conteúdo" de Nutrição que a escola ensina foi classificado como "insuficiente" e "regular". Os temas sugeridos foram. os mesmos para ambos os tipos de escolas, verificando-se grande interesse dos escolares em estudar nutrição. ${ }^{+}$

Mediante consulta aos professores constatou-se que a nutrição ocupou o segundo lugar na escala de prioridades dos temas que devem receber melhor enfoque na escola. ${ }^{+}$

Do exposto, considera-se relevante $e$ urgente que haja um modelo de ensino em Nutrição que atenda as expectativas dos alunos do primeiro grau, em Pernambuco. Portanto, o presente trabalho teve por objetivo propor um modelo de ensino em nutrição que atenda as expectativas dos alunos do primeiro grau, do Estado de Pernambuco.

\section{METODOLOGIA}

A elaboração da proposição constou das seguintes etapas: seleção de objetivos, seleção de conteúdo, técnicas de recursos, bem como de instrumentos para avaliação.

A seleção de objetivos de ensino em nutrição baseou-se, à priori, na interpretação dos resultados do diagnóstico realizado com os alunos da oitava série do primeiro grau. ${ }^{*}$ Uma educação que visa a promoção dos homens considera as suas necessidades antes de determinar os objetivos educacionais 2. Assim, os objetivos selecionados abrangem as áreas do domínio da aprendizagem: congnitiva, afetiva e psicomotora 8.10 .

A seleção dos conteúdos fundamentouse nos temas sugeridos pelos alunos. Segundo Freire ${ }^{3}$, os temas existem nos homens em suas relações com o mundo cabendo ao investigador devolver o universo temático como problema.

O programa proposto traduz as expectativas dos alunos devolvendo-lhes um conteúdo organizado no qual foram considerados os seguintes aspectos: logicidade, gradualidade, continuidade e integração. 
LIMA, E. da S. et al. Educação nutricional na escola do primeiro grau: uma proposição para Pernambuco (Brasil). Rev. Saúde públ., S. Paulo, 20:62-82, 1986.

A seleção e organização das atividades ou experiências de aprendizagem encontra-se relacionada com os objetivos, o conteúdo e o grau de desenvolvimento dos alunos. Deve haver ligação entre a experiência e sua aplicabilidade prática. As sugestões apresentadas no programa incluem atividades de ensino-aprendizagem dentro de um método sócio-individualizado, visando conjugar as vantagens do ensino individual e em grupo ${ }^{1}$.

No que se refere aos recursos educativos, existem muitos meios que podem ser utilizados no ensino da nutrição mediante seleção criteriosa e criativa. Os recursos audivisuais têm por objetivo principal fortalecer o espírito crítico além de despertar o interesse. Quando bem utilizado a serviço do aluno pode promover a aprendizagem.

A avaliação bem como os procedimentos e instrumentos utilizados no processo têm sido discutidos ao longo do tempo. Atualmente ela é considerada como um processo sistemático e contínuo de grande relevância, porque pode proporcionar subsídios para o processo de tomada de decisões e melhoria do ensino ${ }^{5,8}$.

No ensino da nutrição o importante é empregar instrumentos que permitam aos alunos participarem ativa e criticamente das atividades realizadas e do seu aprendizado, incluindo não só a retenção de conhecimentos, mas também a formação de atitudes, valores e responsabilidades. Assim, a avaliação deve ser prioritariamente sinônimo de estímulo para professores e alunos buscarem novas formas de ensino-aprendizagem e educação.

PLANO DE CURSO DE NUTRIÇÃO PARA A ESCOLA DO PRIMEIRO GRAU DE PERNAMBUCO

Nas Tabelas 1 a 8 encontra-se detalhado o modelo proposto de ensino em nutrição para as oito séries do primeiro grau, para o Estado de Pernambuco.

\section{COMENTÁRIOS}

O programa proposto se insere dentro de perspectivas amplas no campo da educação nutricional, vez que atinge a um grupo diretamente envolvido com a problemática da nutrição - os alunos das escolas públicas. Como tal, não se esgota em seus pressupostos, objetivos e conteúdos, devendo ser questionado constantemente com os alunos, de modo a responder com clareza às suas indagações no tocante à realidade dos fatos que perpetuam as suas condições de vulneráveis à desnutrição. Estudo semelhante deve ser estendido aos alunos de segundo grau.

A participação dos pais no processo educativo é importante, a fim de que se estabeleça um vínculo entre o que a escola ensina e a realidade de suas comunidades mediante uma troca de idéias sobre seus problemas de saúde, alimentação e nutrição, bem como os meios de luta existentes para a superação dos mesmos.

E pertinente uma redefinição dos objetivos e conteúdos de "Programas de Saúde", para que representem os principais problemas de saúde da região, de forma prática, lógica e gradual, e que permita aos alunos estabelecerem relações de causa-efeito dentro do contexto social em que vivem.

Apesar da proposta apresentada fornecer subsídios para a realidade de Pernambuco, pode se tornar viável para o Brasil, desde que sejam considerados os aspectos sócio-econômicos e a cultura alimentar de cada região.

Admite-se que a implementação, execução e eficácia da proposta dependerá apenas da predisposição da sociedade em geral e dos educadores em particular para, com os governantes, questionaremse constantemente: $O$ que somos? $O$ que queremos ser? 
LIMA, E. da S. et al. Educação nutricional na escola do primeiro grau: uma proposição para Pernambuco (Brasil). Rev. Saúde públ., S. Paulo, 20:62-82, 1986.

LIMA, E. da S. et al. [Nutritional education in primary schools: a proposal for Pennambuco (Brazil) 1. Rev. Saúde públ., S. Paulo, 20:62-82. 1986.

ABSTRACT: This paper proposes a model the teaching of nutrition in primary schools in the State of Pernambuco, Brazil. Based on the study of the "Science Curriculum Proposal" as well as on the results of a survey conducted among teachers and $8^{\text {th }}$ year students in the metropolitan area of Recife (the state capital), a program for nutrition teaching has been developed that reflects the topics suggested by the students. The elaboration of such a program included: establishment of goals; selection and organization of content; selection of techniques, resources and instruments of evaluation, taking into account such aspects as logical structure, grading, continuity and integration. Topic selection and organization were based on the following general cbjectives: a) $1^{\text {st }}$ year - the understanding that environment, man and food are interdependent; b) $2^{\text {nd }}$ year - the classification of food according to its origin and function and identifying community food resources; c) 3 rd year - the grouping of food according to the predominance of nutrients and their function in the organism, as well as the identification of local food resources; d) 4th year - the identification of forms of food conservation and hygiene and the agricultural and cattle production of the state; e) $5^{\text {th }}$ year - the awareness of general norms for industrial and sanitary food inspection; f) 6th year - the identification of typical local foods as well as different uses of available food resources and their preparation; g) 7 th year - the identification of the factors involved in the access to and adaption of diet suited to the community's nutritional needs; $h$ ) $8^{\text {th }}$ year - the familiarization with the most common nutritional diseases in Pernambuco as well as in Brazil in general, their determinant factors, consequences and preventive measures to be taken. The program proposed can be added to the Health Program, each grade (year) corresponding to one of the units of those in this study area.

UNITERMS: Child nutrition. Health education. Child. School.

\section{REFERENCIAS BIBLIOGRĀFICAS}

1. CARVALHO, I.M. O processo didático. 3. a ed. Rio de Janeiro, Fundação Getúlio Vargas, 1979. p. 137-93

2. FREIRE, P. Extensão ou comunicação? 6. ${ }^{\mathrm{a}}$ ed. São Paulo, Paz e Terra, 1982. p.24-36.

3. FREIRE, P. Pedagogia do oprimido. $11 .^{\mathrm{a}}$ ed. Rio de Janeiro, Paz e Terra, 1982. p. 29-61.

4. LIMA, E. da S. et al. Educação nutricional na escola de primeiro grau em Pernambuco (Brasil): diagnóstico. Rev. Saúde públ., S. Paulo, 19:508-20, 1985.

5. NERICI, I. Didática geral dinâmica. 9. a ed. São Paulo, Atlas, 1983. p. 204-49.

6. REFLEXIONES sobre educacion alimentar e nutricional. Boletin PIA/PNAN, $(6 / 7): 1-7,1979$.
7. SAVIANI, D. Educação: do senso comum à consciência filosófica. 2. a ed. São Paulo, Cortez, 1982. p. 133-6.

8. SCHIMITZ, E. I. Didática moderna: fundamentos. Rio de Janiero, Livros Técnicos e Científicos, 1982. p. 106-11; 149-66.

9. SECRETARIA DE EDUCAÇÃO E CULTURA. Proposta curricular; Ensino de $1 .^{\circ}$ grau: Ciências. 2. ${ }^{\mathrm{a}}$ ed. Porto Alegre. 1978.

10. TURRA. C.M.G. et al. Planejamento de ensino e avaliação. 10. ${ }^{\mathrm{a}} \mathrm{ed}$. Porto Alegre. Laga, 1982. p. 57-98.

Recebido para publicação em 19/08/1985

Aprovado para publicação em 08/11/1985 


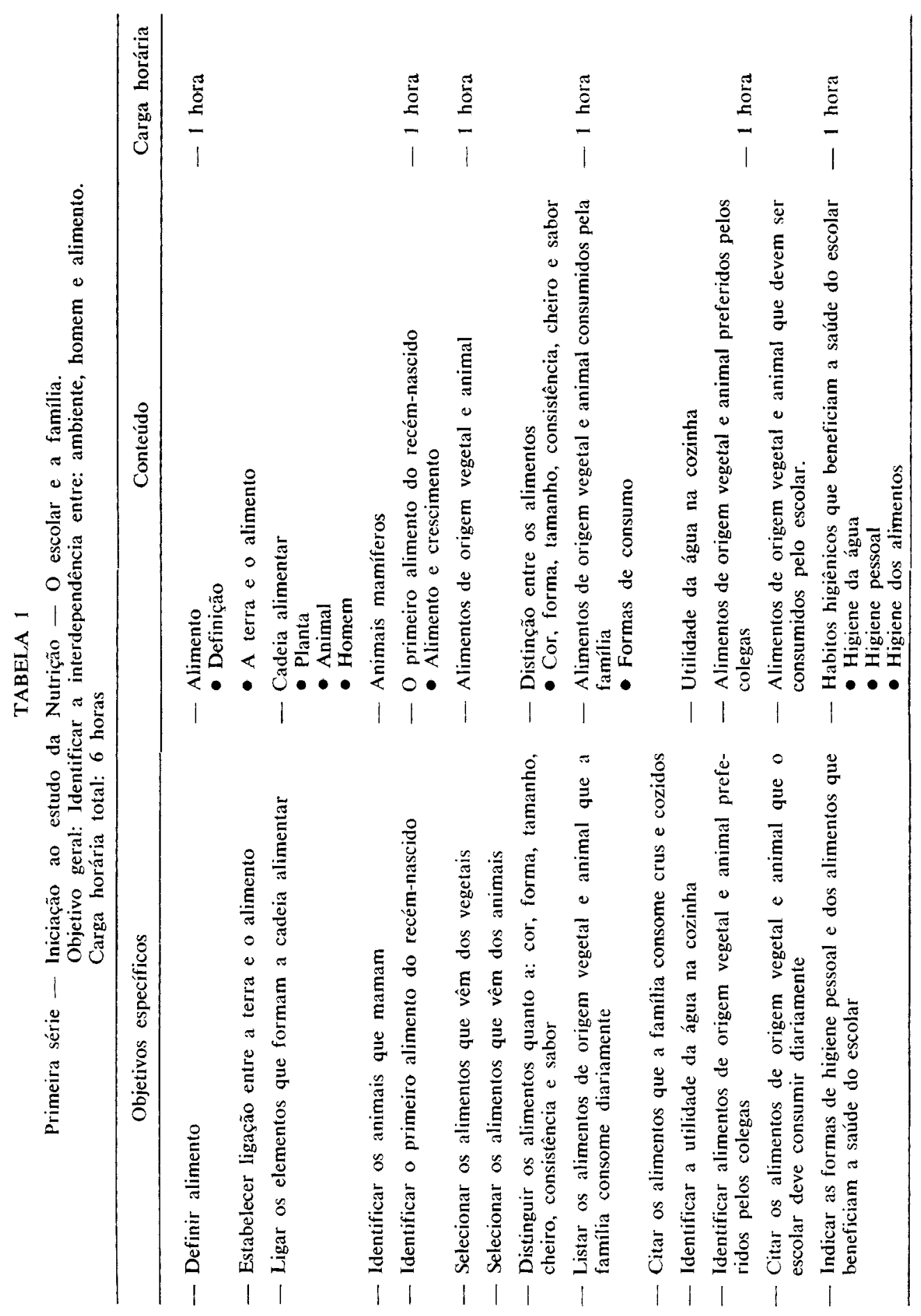


LIMA, E. da S. et al. Educação nutricional na escola do primeiro grau: uma proposição para Pernambuco (Brasil). Rev. Saúde públ., S. Paulo, 20:62-82, 1986.

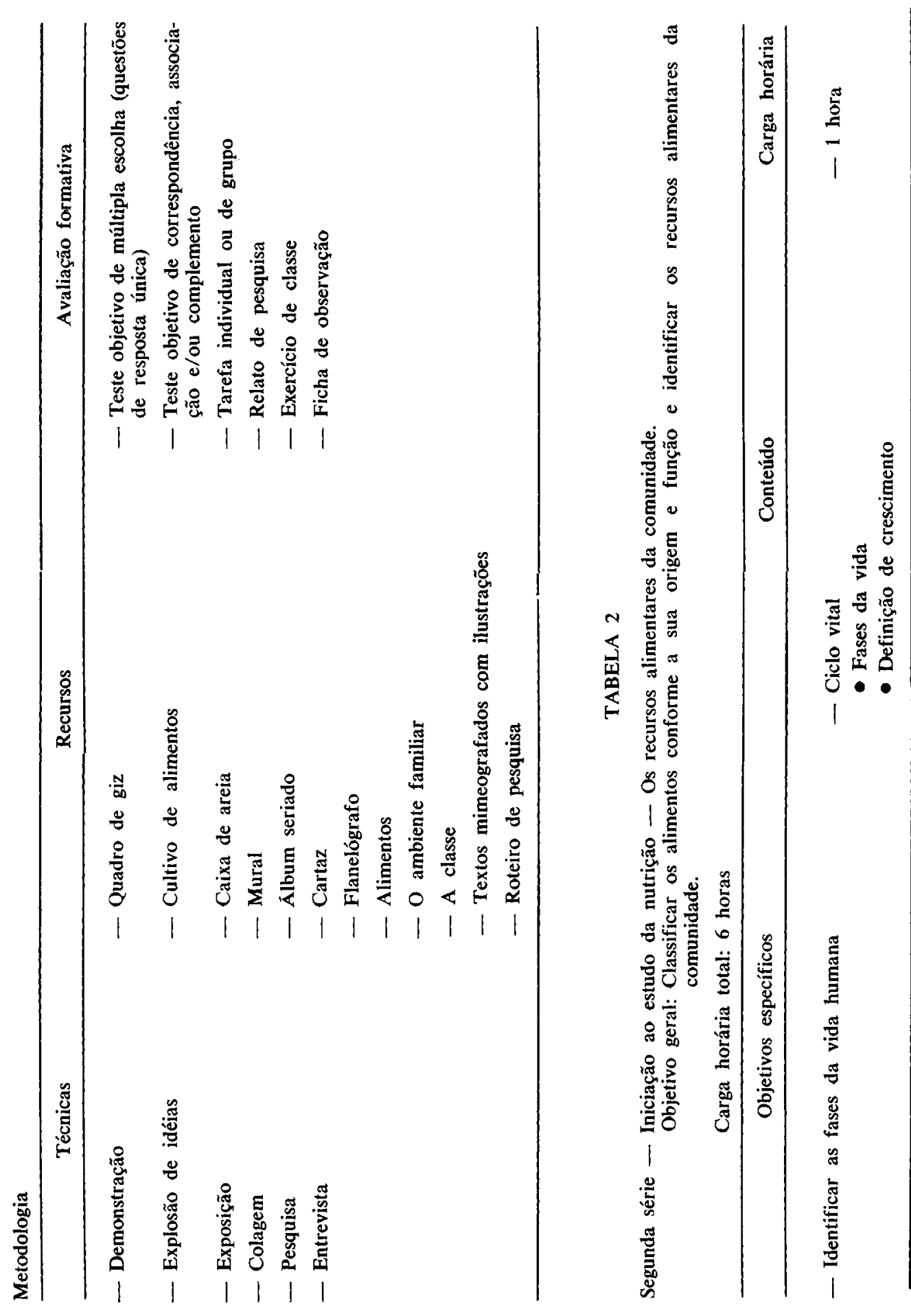




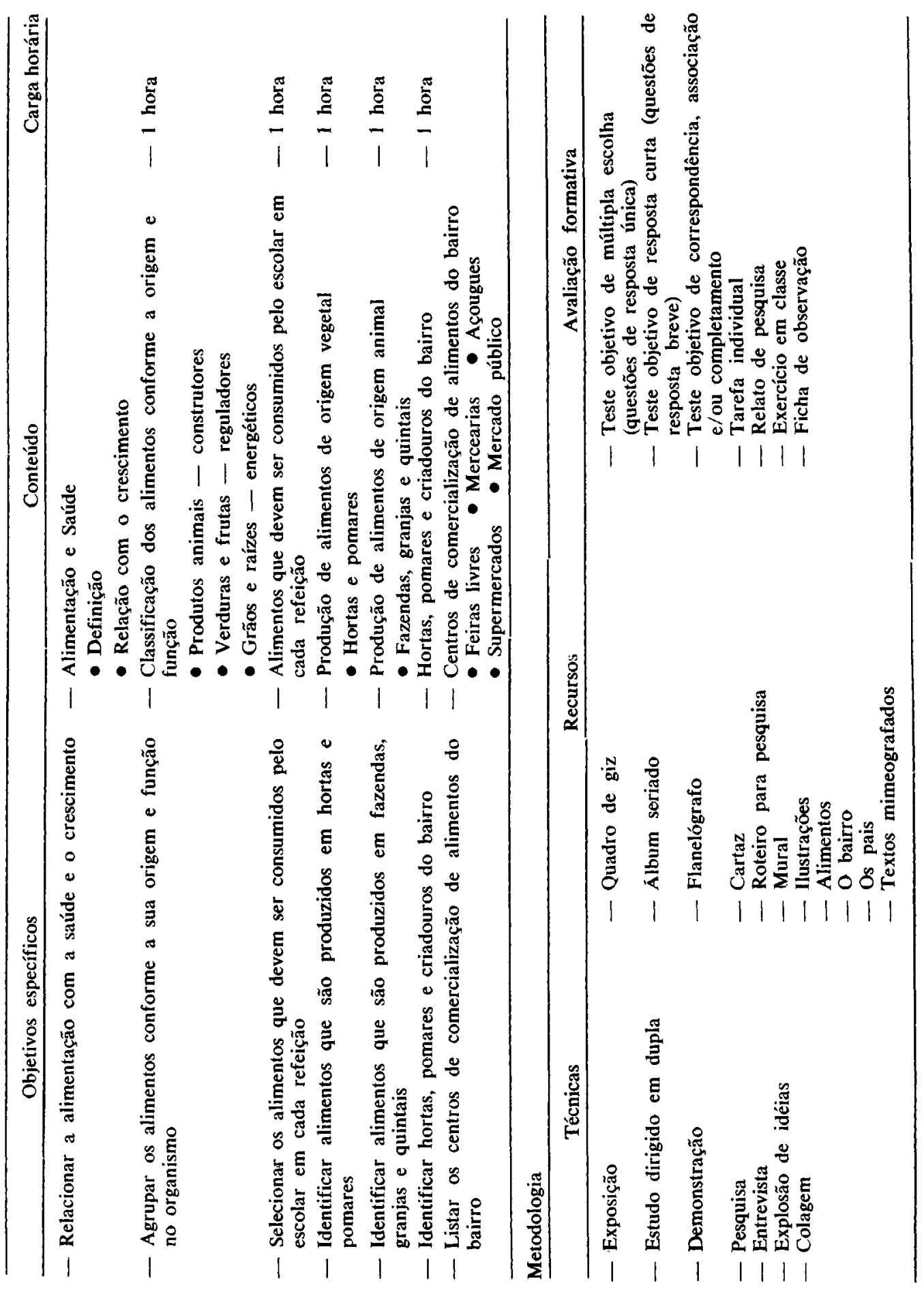




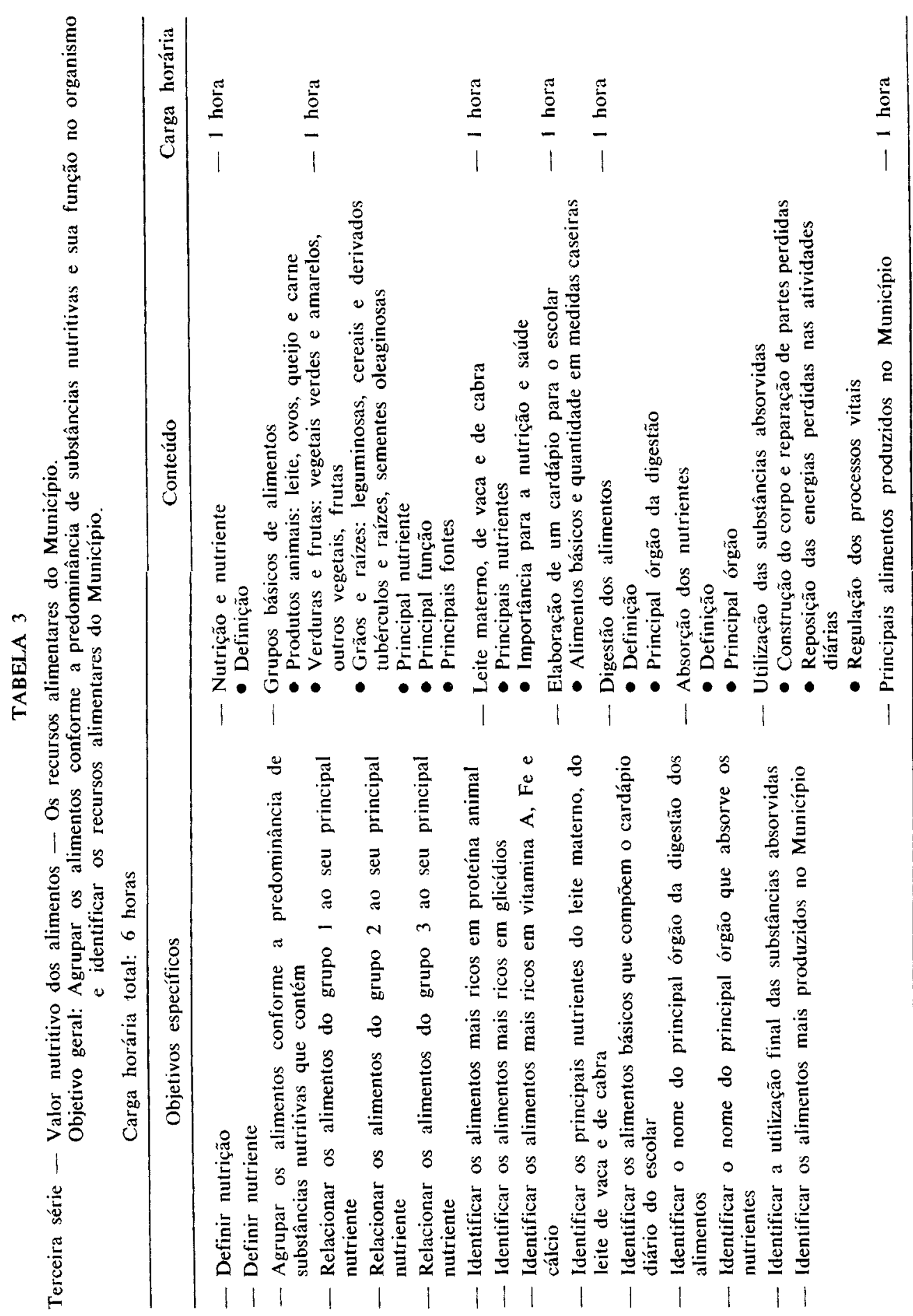



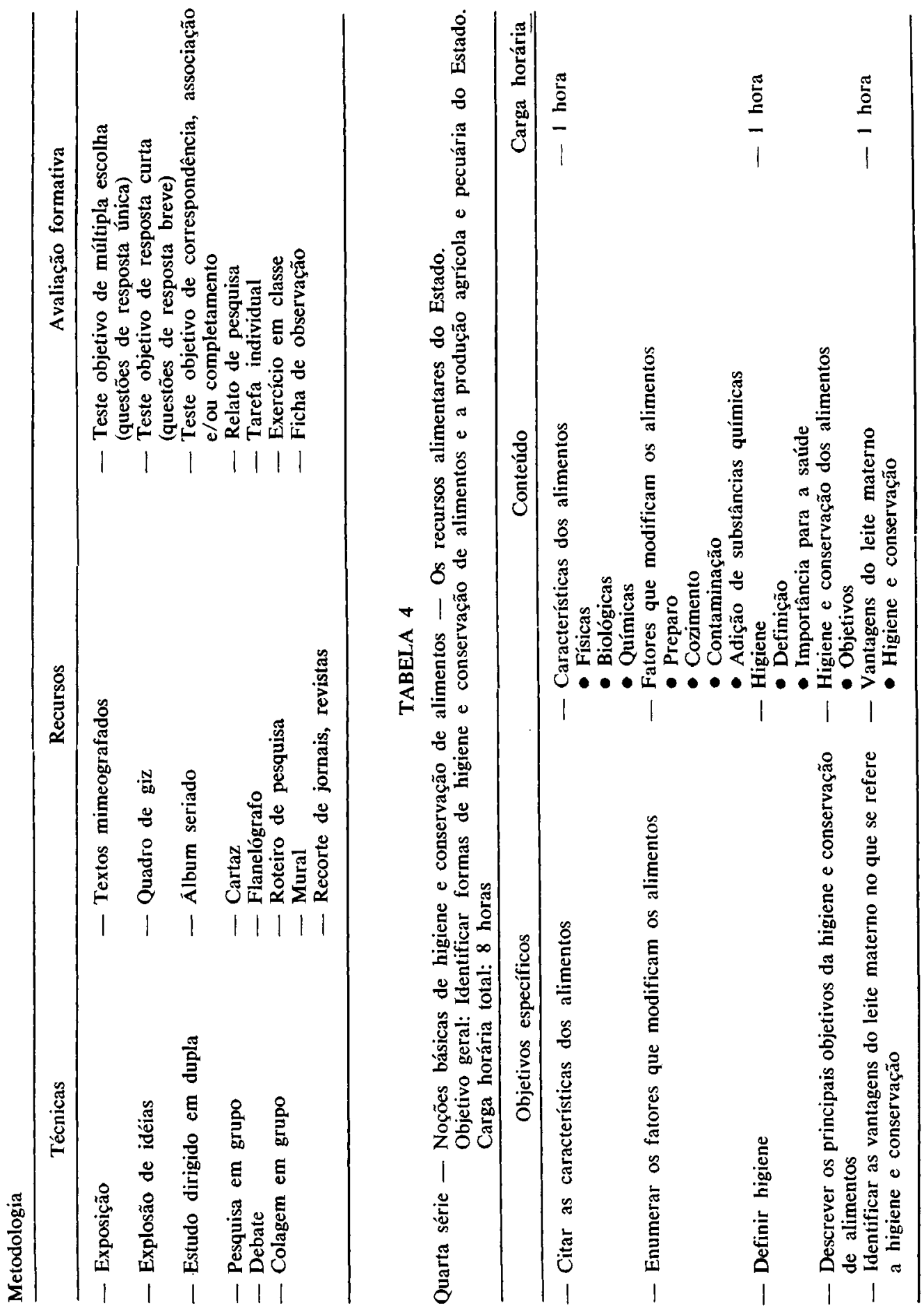
LIMA, E. da S. et al. Educação nutricional na escola do primeiro grau: uma proposição para Pernambuco (Brasil), Rev. Saúde públ., S. Paulo, 20:62-82, 1986.

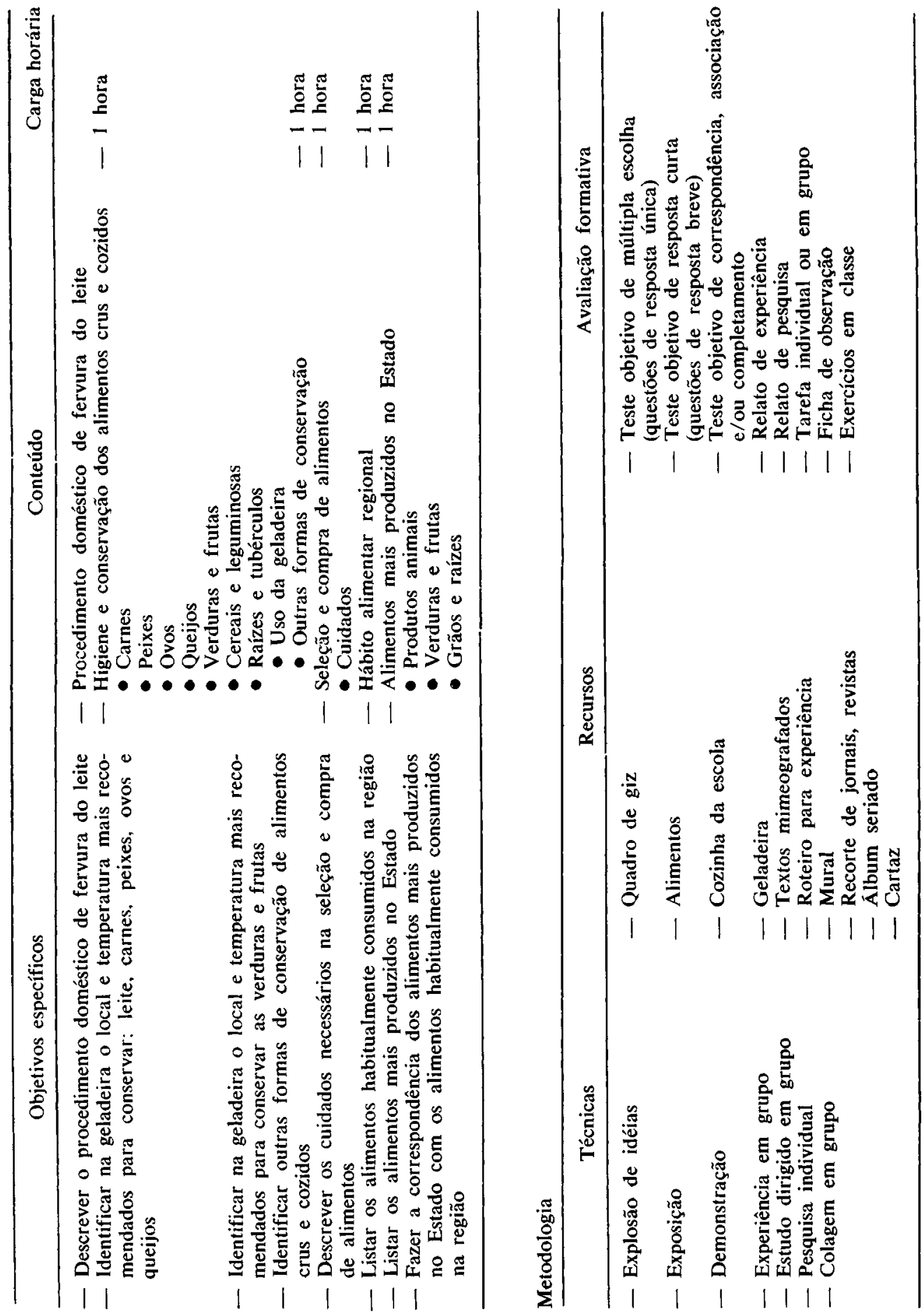




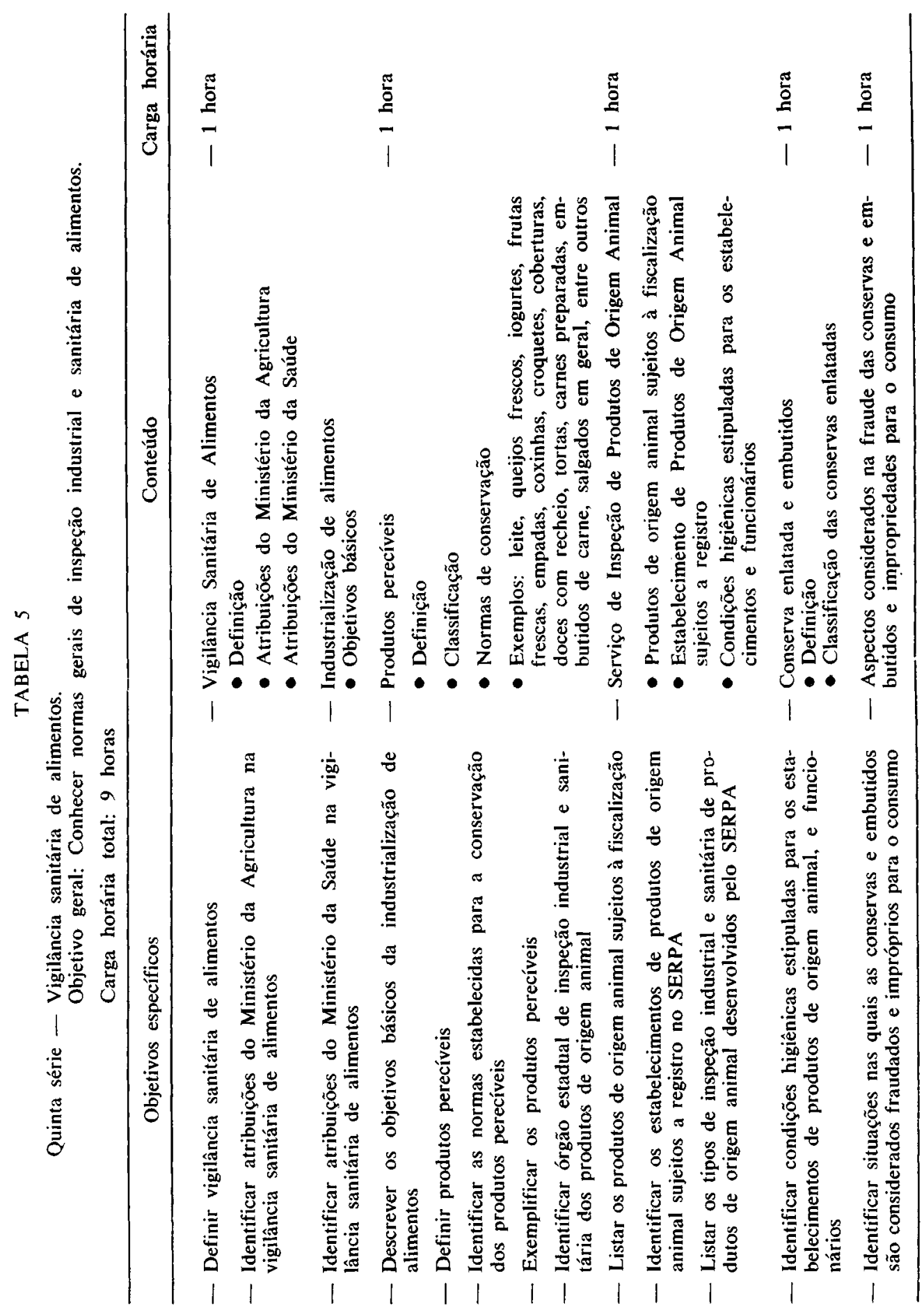


LIMA, E. da S. et al. Educação nutricional na escola do primeiro grau: uma proposição para Pernambuco (Brasil). Rev. Saúde públ., S. Paulo, 20:62-82, 1986.
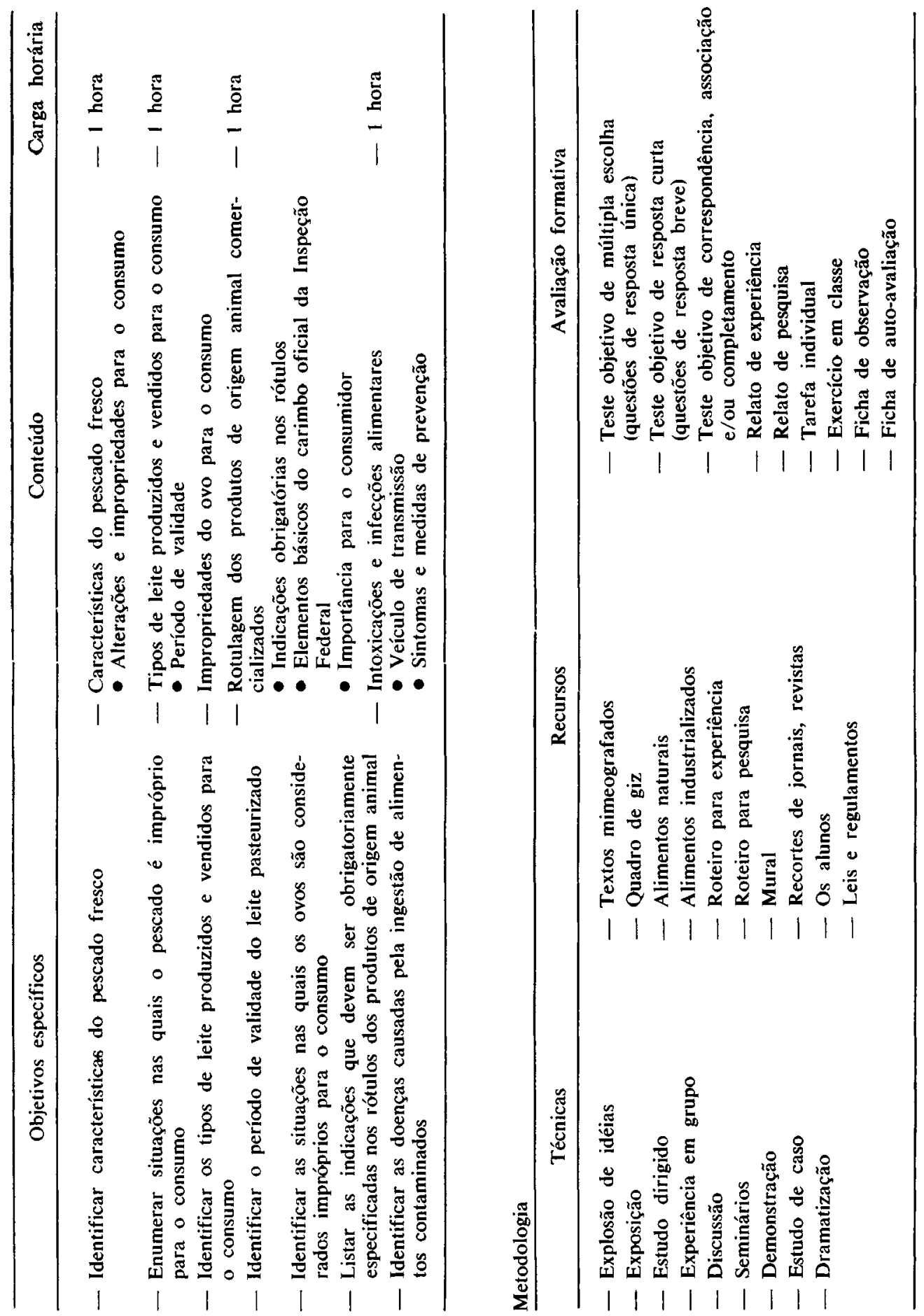


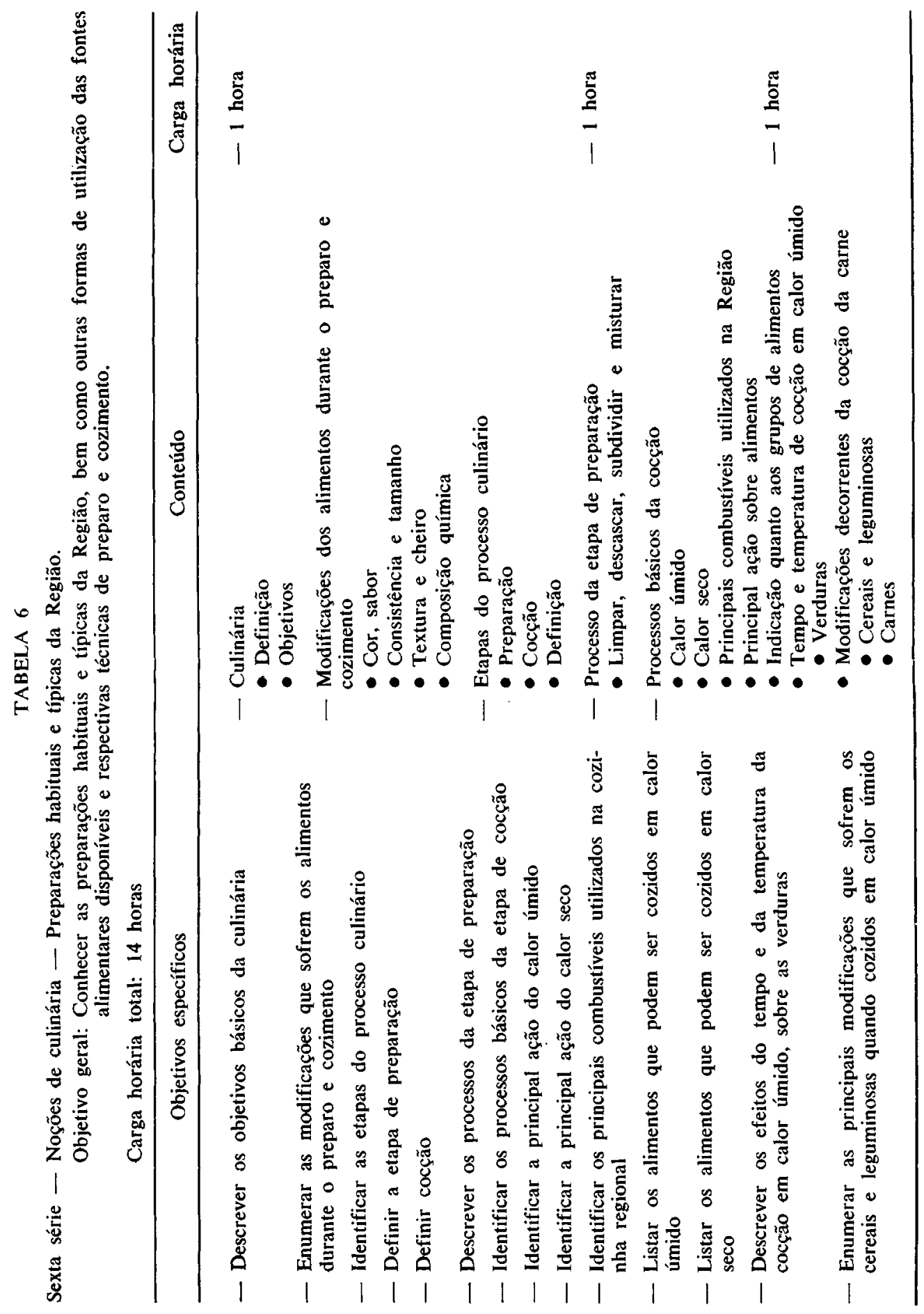


LIMA, E. da S. et al. Educação nutricional na escola do primeiro grau: uma proposição para Pernambuco (Brasil). Rev. Saúde públ., S. Paulo, 20:62-82, 1986.

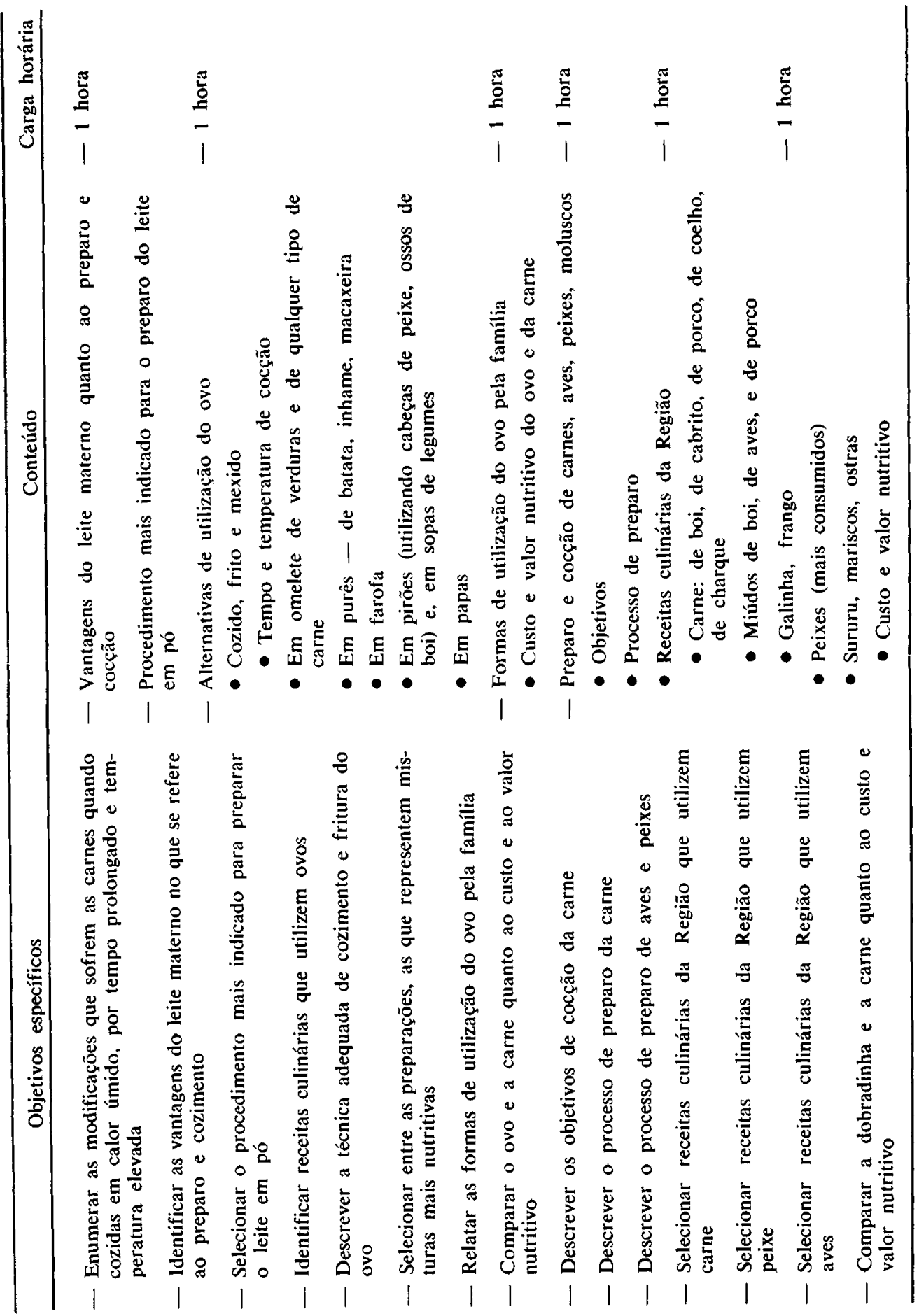




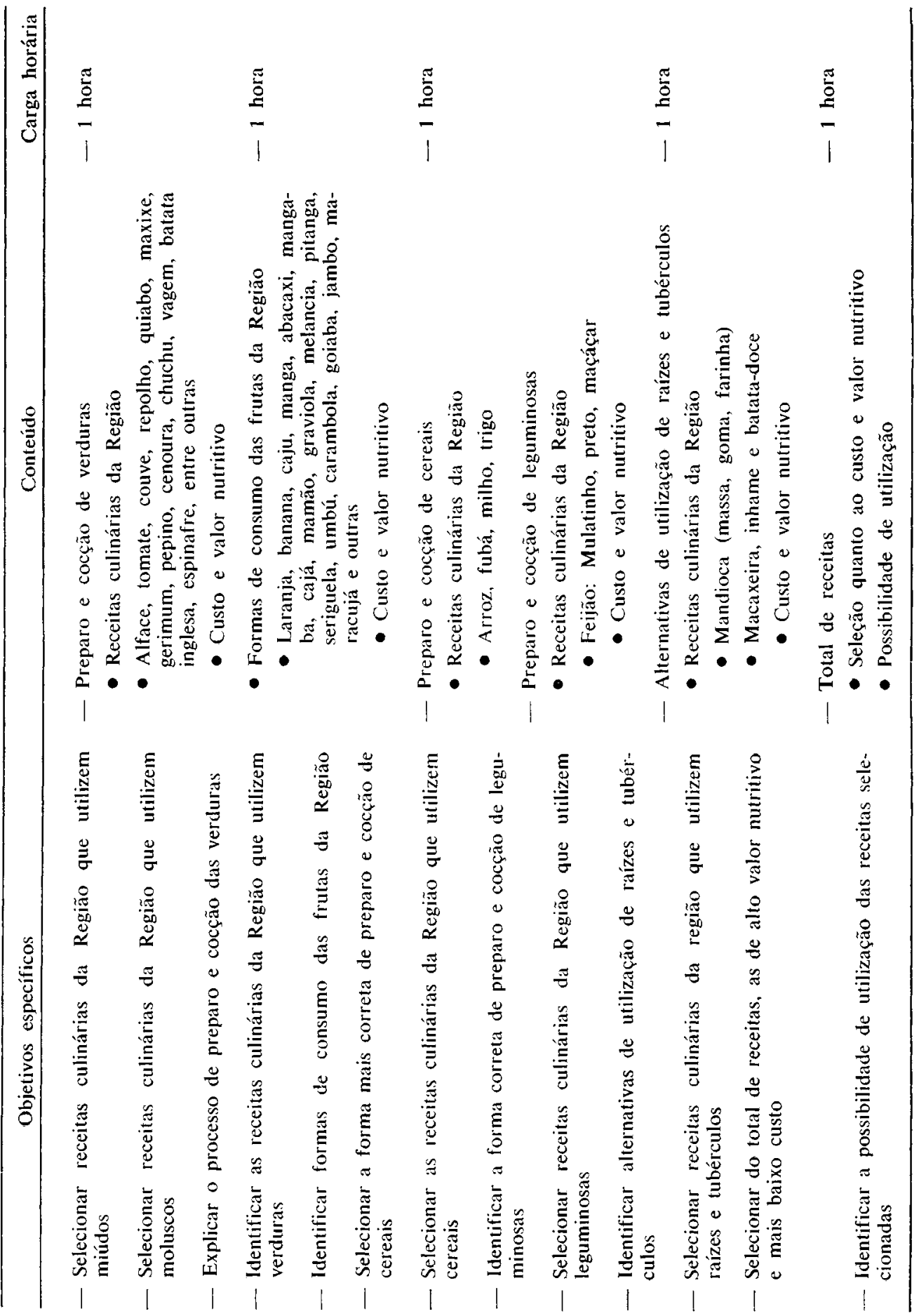


LIMA, E. da S. et al. Educação nutricional na escola do primeiro grau: uma proposição para Pernambuco (Brasil). Rev. Saúde públ., S. Paulo, 20:62-82, 1986.
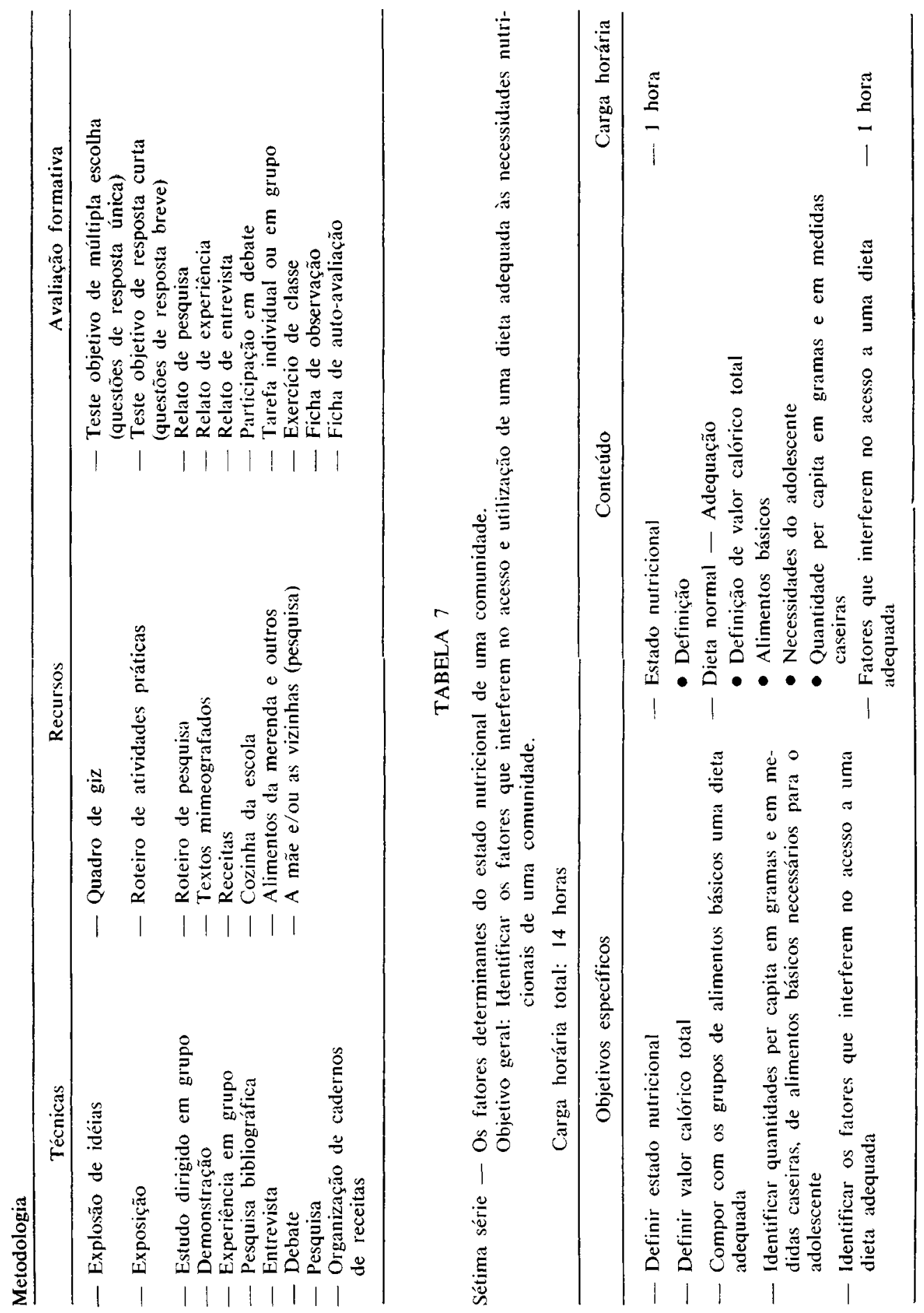


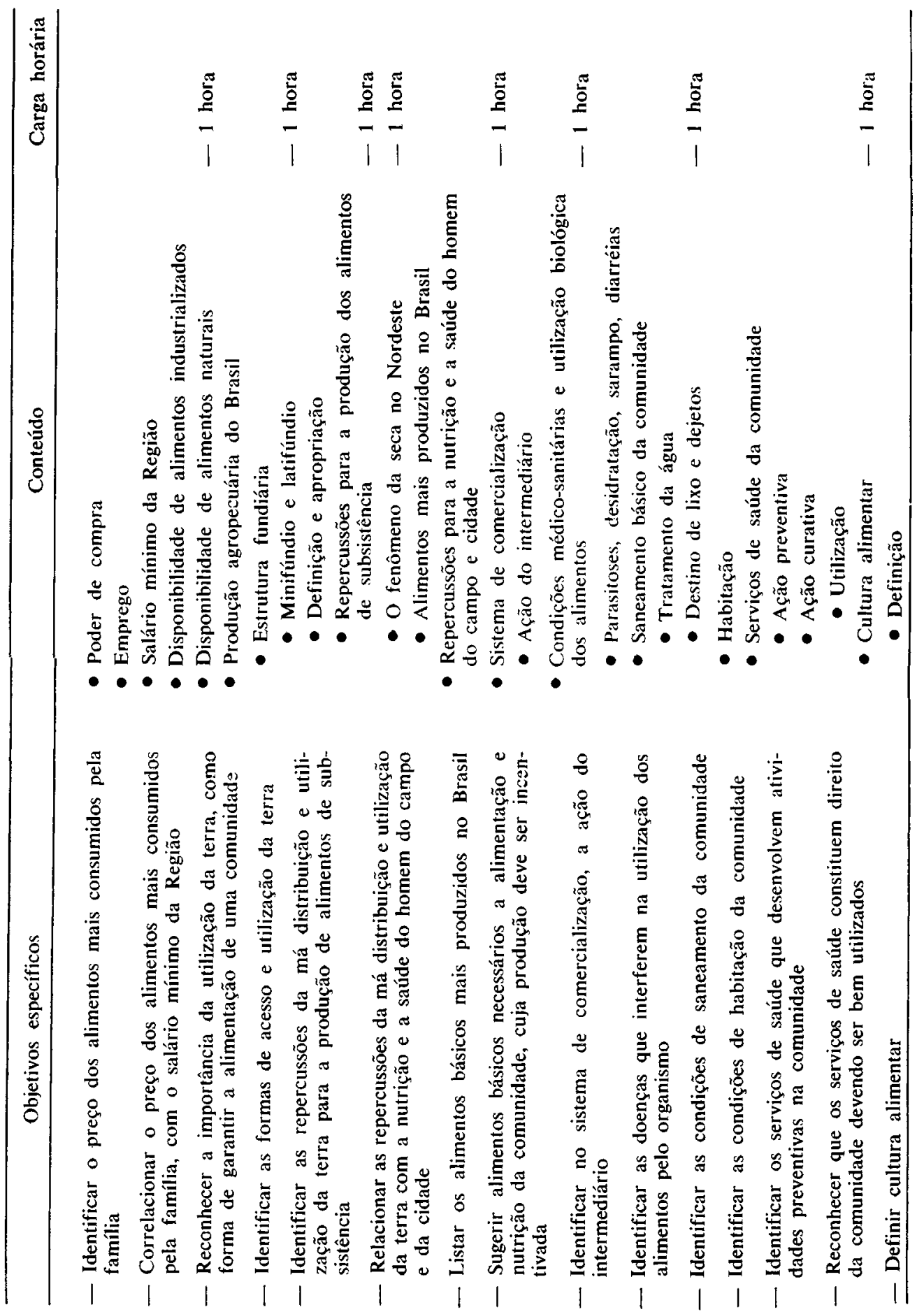


LIMA, E. da $S$. et al. Educação nutricional na escola do primeiro grau: uma proposição para Pernambuco (Brasil). Rev. Saúde públ., S. Paulo, 20:62-82, 1986.

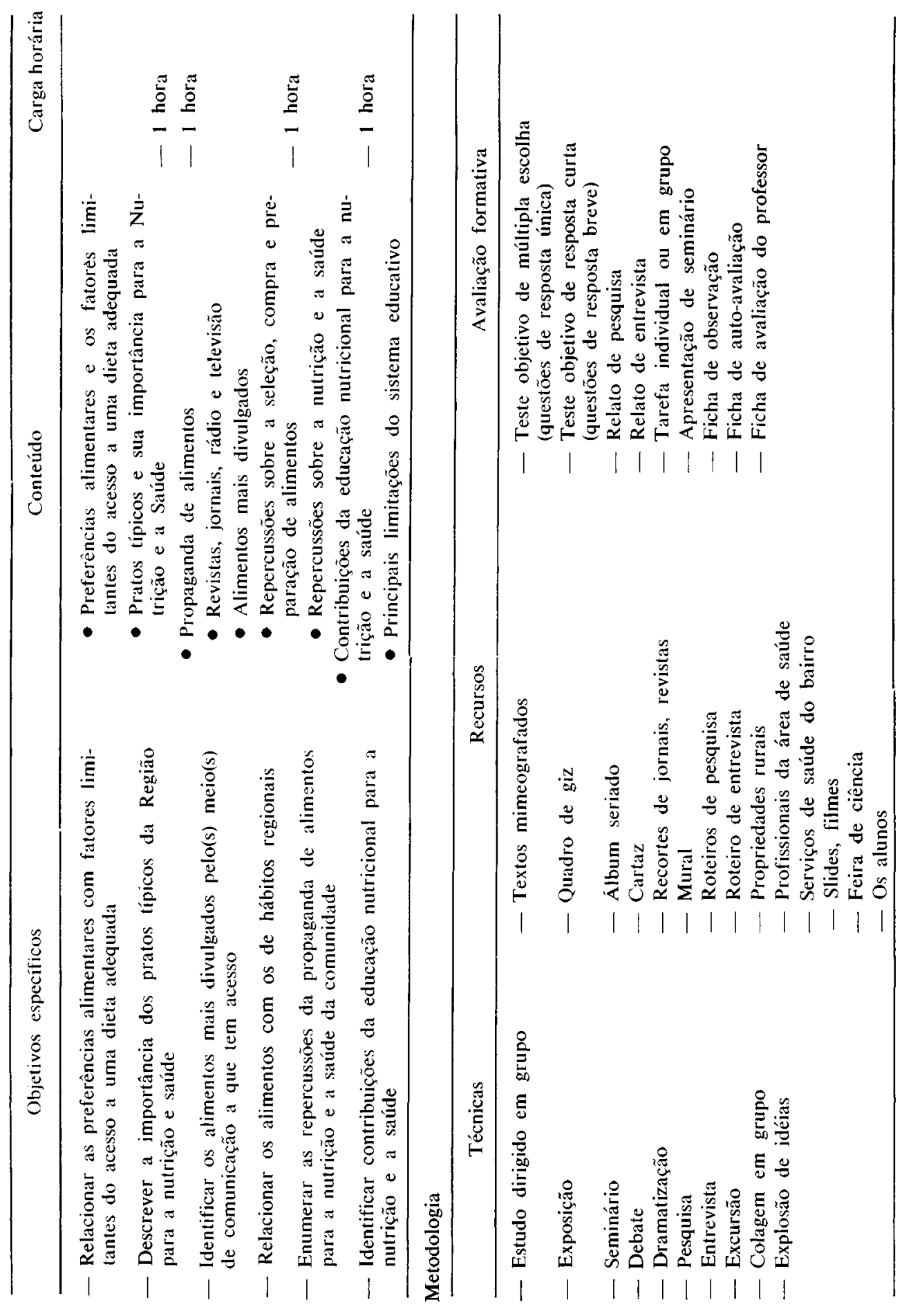




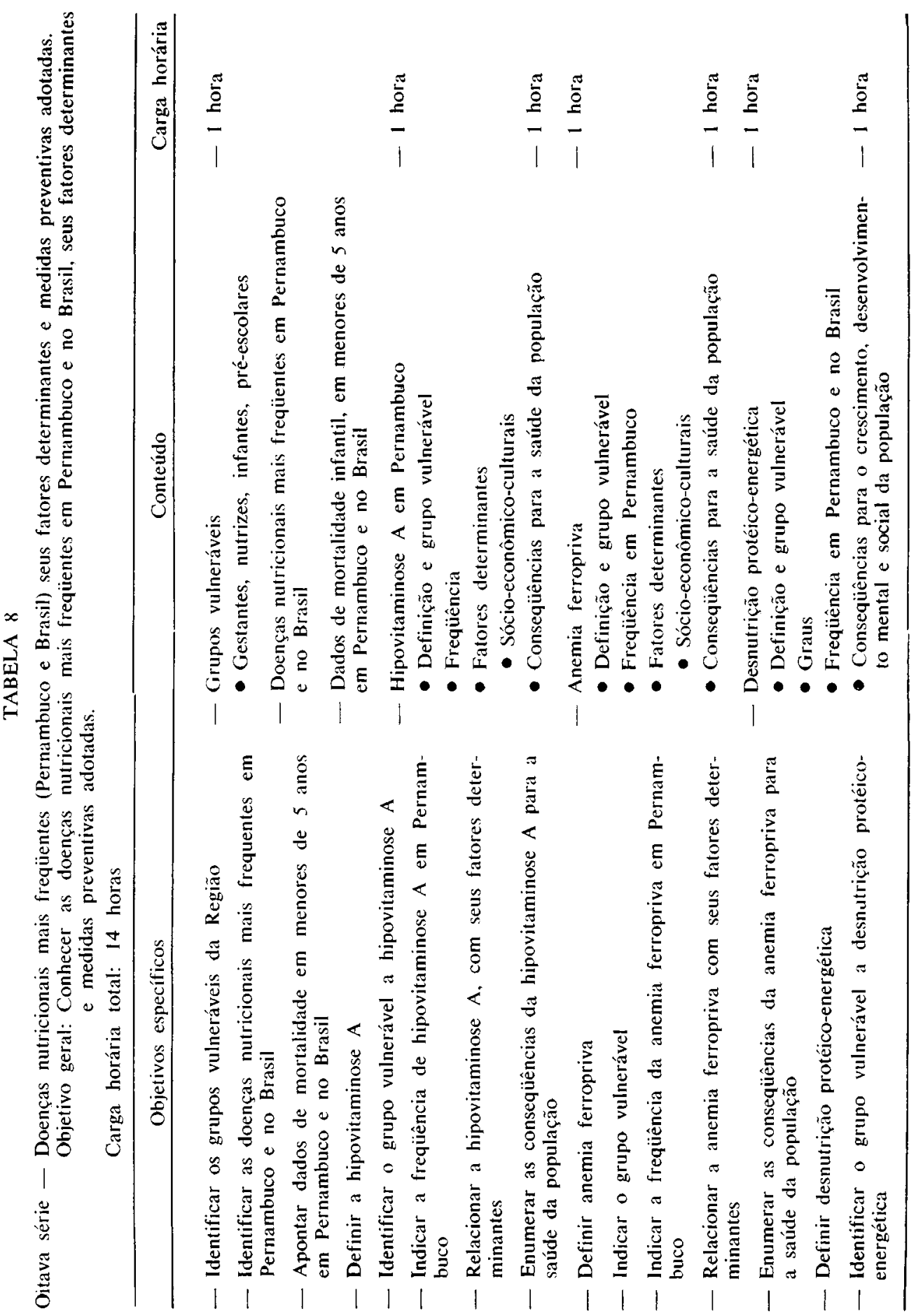


LIMA, E. da S. et aḷ. Educação nutricional na escola do primeiro grau: uma proposição pará Pernambuco (Brasil). Rev. Saúde públ., S. Paulo, 20:62-82, 1986.

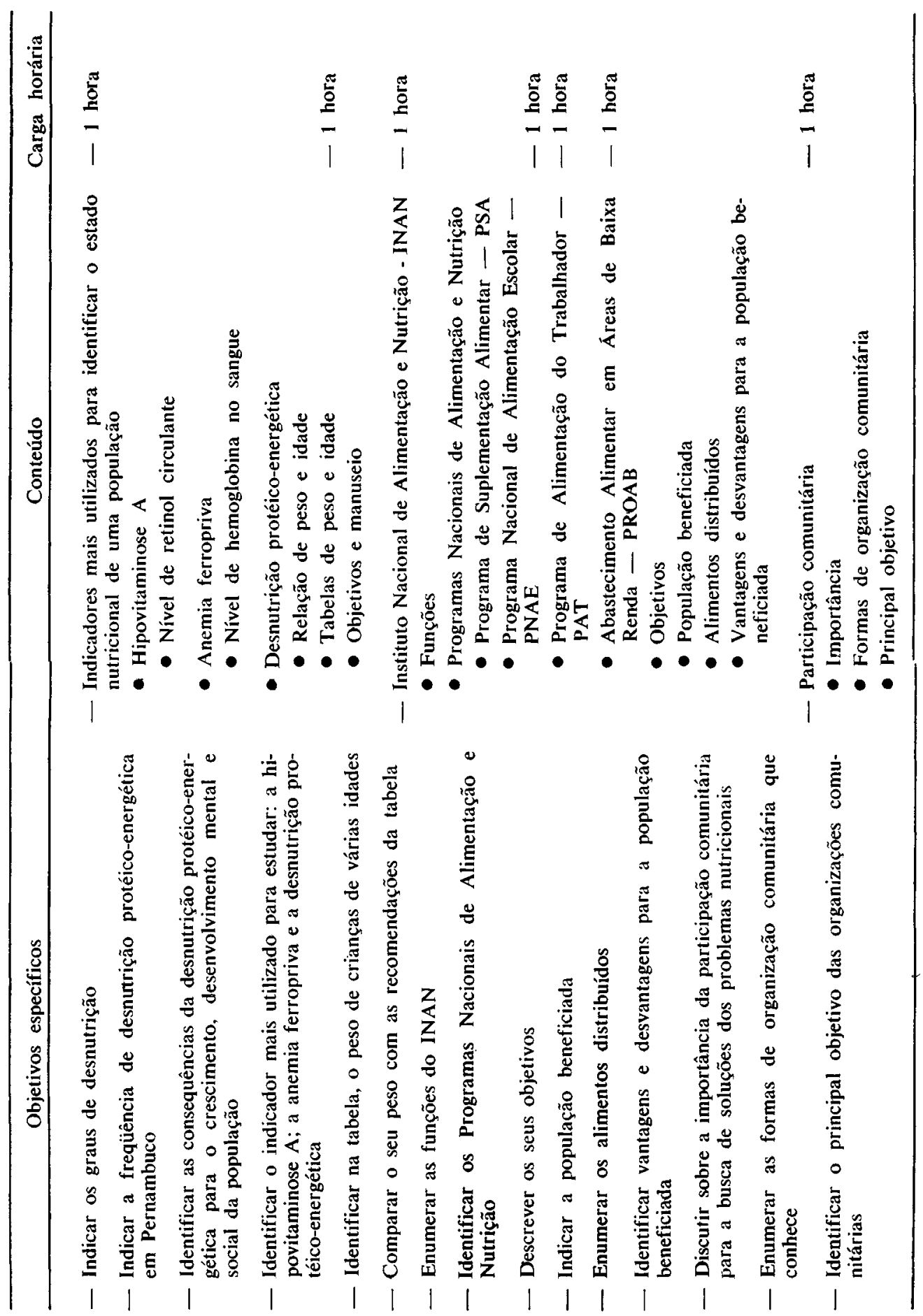


LIMA, E. da S. et al. Educação nutricional na escola do primeiro grau: uma proposição para Pernambuco (Brasil). Rev. Saúde públ., S. Paulo, 20:62-82, 1986.

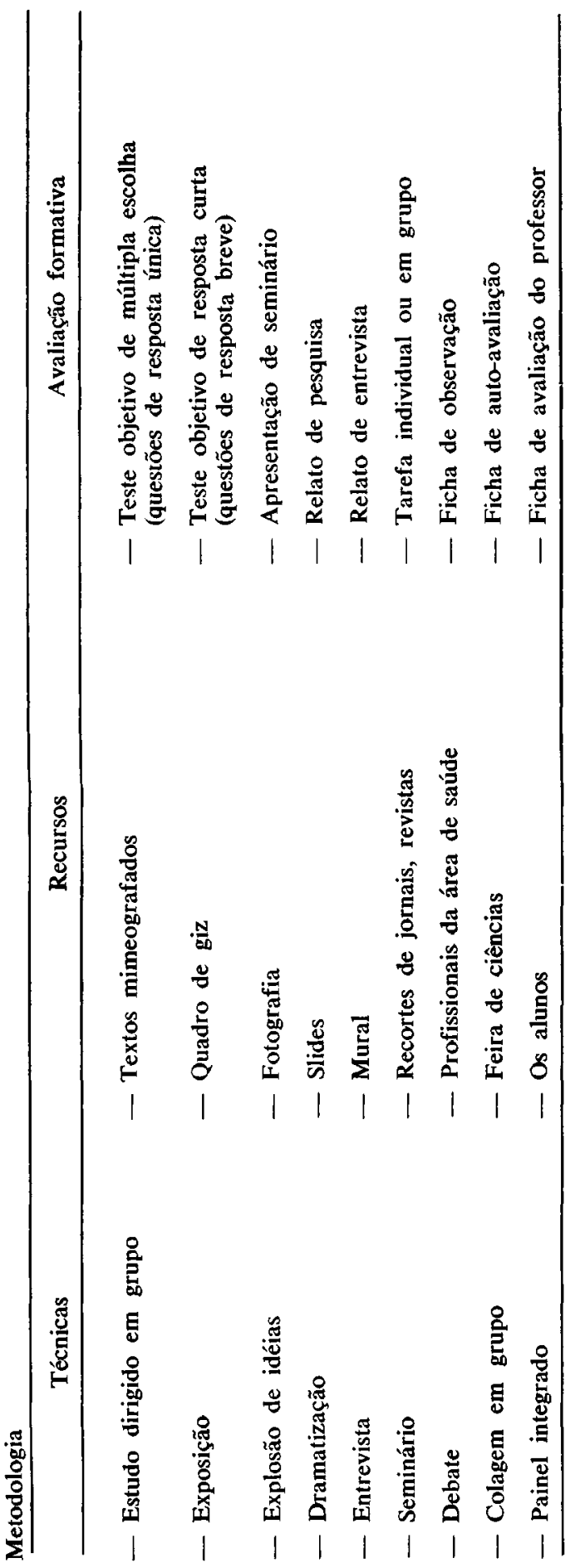

